\title{
Application of an inexpensive and high-throughput genomic DNA extraction method for the molecular ecology of zooplanktonic diapausing eggs
}

\author{
Javier Montero-Pau',2, Africa Gómez ${ }^{1 *}$, and Joaquín Muñoz ${ }^{1,3}$ \\ ${ }^{1}$ Department of Biological Sciences, University of Hull, Hull, HU6 7RX, UK \\ ${ }^{2}$ Institut Cavanilles de Biodiversitat i Biologia Evolutiva, Universitat de València, A.O. 2085, 46071, Valencia, Spain \\ ${ }^{3}$ Laboratory of Molecular Ecology, Estación Biológica de Doñana (CSIC), Pabellón del Perú, Avda. María Luisa, s/n., 41013, \\ Seville, Spain
}

\begin{abstract}
We describe the application of a simple, low-cost, and effective method of DNA extraction (hot sodium hydroxide and Tris, HotSHOT) to the diapausing propagules of continental aquatic invertebrates for its use in PCR amplification. We illustrate the use of the technique in cladocerans, rotifers, anostracans, notostracans, and copepod diapausing eggs. We compare the performance of the HotSHOT technique to the currently most widely used method for DNA extraction of zooplankton eggs and individuals, the chelating resin (or Chelex) technique. The HotSHOT technique overcomes several of the problems posed by Chelex and permits easy optimization for its use with 96-well plates for high-throughput DNA extraction and subsequent genetic characterization. We foresee a wide use of this technique in the future from DNA barcoding of diapausing stages to the genetic characterization of the diapausing egg banks of continental aquatic invertebrates.
\end{abstract}

In recent years, an explosive development of high-throughput, relatively cheap, molecular techniques for the scoring of microsatellites, AFLPs, SNPs, and sequencing has taken place. These technological advances have spurred population-level analysis from phylogeography and population structure to barcoding and large-scale multigene sequencing projects, all key areas of ecological and evolutionary research. The development of methods to prepare DNA extractions in a quick, simple, cost-effective and high-throughput way has shown a parallel progress for model organisms including human forensic material (Walsh et al. 1991; Rudbeck and Dissing 1998), mouse (Truett et al. 2000), and Arabidopsis and crop plants

${ }^{*}$ Corresponding author: E-mail a.gomez@hull.ac.uk

\section{Acknowledgments}

We thank D. Lunt for suggesting the use of HotSHOT, for technical help, and for providing old Daphnia samples. We are grateful to T. Zierold for providing Triops samples and F. Amat for providing Artemia cysts. Rob Hammond is kindly thanked for his constructive comments on an earlier version of this manuscript. We also thank the valuable comments and suggestions by two anonymous reviewers. This study was partly funded by a NERC Advanced Fellowship to AG. JM was supported in his stay in Hull by the Spanish Ministerio de Educación y Ciencia project (project CGL2006-05085/BOS) to A.J. Green, C. Rico, F. Hontoria and J. Figuerola. The Spanish Ministerio de Educación y Ciencia supported JMP during his stay in the University of Hull.
(Xin et al. 2003), but their wider application for molecular ecology is timely.

Molecular genetic surveys of continental aquatic invertebrates (cladocerans, anostracans, rotifers, copepods, ostracods, etc.) have yielded valuable insights into the evolutionary forces shaping their genetic structure and microevolution (De Meester et al. 2002; Gómez 2005; Ishida and Taylor 2007), and are helping to characterize the cryptic biodiversity of these groups (Gómez et al. 2002; Adamowicz and Purvis 2005). Continental aquatic invertebrates cope with the temporal character and unpredictability of their habitats by producing diapausing stages. Diapausing eggs — which are encysted embryos in arrested state of development, also called cysts or resting eggsare resistant to a wide range of environmental extremes (Proctor et al. 1967; Carlisle 1968), and are long-lived dormant stages in pond and lake sediments, forming diapausing egg banks (Hairston 1996). For many molecular genetic surveys in these organisms, sampling diapausing egg banks in populations is a useful or even the only way of obtaining population or species level genetic information. Given the ephemeral nature of many aquatic habitats, the year-round availability of diapausing stagesas opposed to often ephemeral planktonic stages-is a great advantage for their use. Furthermore, when the ponds and lakes are sampled during dry periods, they represent the best sample of the population gene pool (Moorad et al. 1997; Gómez et al. 2000; 
Table 1. Details of samples used for Fig. 1.

\begin{tabular}{|c|c|c|c|c|}
\hline Species & Location & Sampling date & Sample & Preservation \\
\hline Artemia salina & Cagliari, Sardinia, Italy & May 2004 & Plankton & Dry/Ethanol* \\
\hline Artemia salina & Trapani, Sicily, Italy & May 1985 & Plankton & Dry/Ethanol* \\
\hline Brachionus plicatilis & Laguna de Pétrola, Albacete, Spain & November 2004 & Sediment & Live/salt water $\dagger$ \\
\hline Daphnia magna & Pearson Park Pond, Hull, United Kingdom & June 2007 & Plankton & Live \\
\hline Daphnia magna & Pearson Park Pond, Hull, United Kingdom & August 2000 & Plankton & Ethanol \\
\hline Triops cancriformis & Königswartha Pond 12, Germany & 2005 & Culture & Live \\
\hline Unidentified copepod & Laguna de Fuente de Piedra, Málaga, Spain & June 1999 & Sediment & Live \\
\hline
\end{tabular}

*Samples were obtained as dried resting eggs and transferred to $100 \%$ ethanol in 2004.

†Samples were extracted from sediments using a sugar-flotation technique (see text for details) and stored in $60 \mathrm{~g} / \mathrm{L}$ salt water at $4^{\circ} \mathrm{C}$ in the dark in 2004 .

Ortells et al. 2000). In addition, and conveniently, sediment samples containing living diapausing stages can be maintained in the laboratory for long periods of time. Finally, old diapausing stages from lake and pond sediment cores are a repository of the historical genetic constitution of past populations, and their use for genetic analysis has revealed much valuable information from historical changes in the environment, the dynamics of Daphnia communities, adaptive changes in antipredator behavior, alien invasions to the dynamics of coexistence of cryptic species (Duffy et al. 2000; Reid et al. 2000; Cousyn et al. 2001; Limburg and Weider 2002; Mergeay et al. 2004; JM-P, unpublished manuscript).

Although the importance of sampling diapausing stages was realized a while ago (Carvalho and Wolf 1989; Hairston 1996), the genetic characterization of diapausing egg banks depended on hatchlings obtained in the laboratory to obtain sufficient biomass for genetic analysis, as DNA extractions from such small samples remained a challenge. Ideally, DNA extraction techniques from individual diapausing stages should obtain reliable results from a very small amount of tissue (for example, rotifer diapausing stages are less than $100 \mu \mathrm{m}$ in length) using as few tube transfers as possible to avoid contamination of samples. A chelating resin method (using Chelex® 100 resin or InstaGene matrix, Bio-Rad) (Walsh et al. 1991), originally developed to extract DNA from forensic material, has been, and remains to this date, the most widely used method to prepare DNA from diapausing stages and individual zooplankton in rotifers (Gómez and Carvalho 2000; Fontaneto et al. 2007), Daphnia (Taylor et al. 1996; Reid et al. 2000), copepods (Edmands 2001; Bohonak et al. 2006), anostracans (Moorad et al. 1997) and ostracods (Yamaguchi 2000). However, various problems become apparent when working with this method. Resin beads inhibit polymerase chain reaction (PCR). Therefore, in order to use high-throughput 96-well plates for PCR amplification using multichannel pipettes, centrifugation and transfer of the sample supernatant into fresh tubes or plates is needed after extraction and before preparing PCR reactions. This increases preparation time and cost, and the chances of contamination. In addition, and more importantly, the technique does not produce a stable DNA extract, and samples often deteriorate with time and become unusable for PCR (Greenspoon et al. 1998; Hajibabaei et al. 2005) unless buffered (Söller et al. 2000).

Here we describe an optimized alkaline lysis protocol to produce inexpensive, rapid, and simple DNA extractions that avoid the above-mentioned problems. This protocol produces reliable DNA extractions that can be used to conduct PCRbased genetic screening (e.g., mitochondrial DNA and microsatellite amplification) on large samples of diapausing stages of zooplanktonic organisms. The HotSHOT technique (Truett et al. 2000), a modified alkaline lysis method (Sambrook and Russell 2001), is a reliable, cheap, and simple DNA extraction technique that can be easily adapted to aquatic invertebrates organisms with diapausing propagules. An additional advantage is that, being a single-tube technique, the likelihood of cross-contamination is reduced. We demonstrate the use of this technique for diapausing stages in zooplankton and illustrate its efficiency with cysts or diapausing eggs of cladocerans, rotifers, copepods, anostracans and notostracans, both for fresh and preserved material. In addition, we compare directly the efficiency of the technique with the widely used Chelex resin method.

\section{Materials and procedures}

Biological material-Diapausing eggs were obtained from plankton samples from natural populations. Eggs were extracted from lake sediments using a sucrose-flotation technique (Onbé 1978; Gómez and Carvalho 2000), or taken directly from laboratory cultures (see Table 1 for details). We obtained samples of five different groups of aquatic invertebrates: rotifers (Brachionus plicatilis), cladocerans (Daphnia magna), anostracans (Artemia salina), notostracans (Triops cancriformis), and copepods (unidentified species). Mature Daphnia ephippia were separated from their mothers and diapausing eggs manually decapsulated. The diapausing eggs of these organisms have a range of sizes from under $100 \mu \mathrm{m}$ to ca. $400 \mu \mathrm{m}$. Some of the diapausing eggs had been preserved in ethanol $100 \%$, some were collected fresh from mature females, and others had been stored dry and in the dark or in sediment samples. A few samples had been kept in the laboratory for several years, either in dormant (live) state or fixed (Table 1). 
Table 2. Procedure of the HotSHOT method applied to diapausing stages.

1. Aliquot $50 \mu \mathrm{L}$ of alkaline lysis buffer $(\mathrm{NaOH} 25 \mathrm{mM}$, disodium EDTA $0.2 \mathrm{mM}, \mathrm{pH} 8.0$ ) into $0.2 \mathrm{~mL}$ individual tubes.

2. Under a stereomicroscope, transfer individual diapausing eggs to the tubes with a pipette using the minimum amount of liquid to carry the egg (e.g., $2 \mu \mathrm{L})$.

3. Using a sterile pipette tip, crush the egg against the side of the tube to release the embryo.

4. Incubate for $30 \mathrm{~min}$. at $95^{\circ} \mathrm{C}$, and then cool on ice for 3-4 min.

5. Add $50 \mu \mathrm{L}$ neutralizing solution (Tris- $\mathrm{HCl} 40 \mathrm{mM}, \mathrm{pH} 5.0$ ).

6 . Vortex the tubes to mix and spin.

7. Use $2 \mu \mathrm{L}$ for PCR or freeze at $-20^{\circ} \mathrm{C}$ for long-term storage.

DNA extraction protocol- Prior to the DNA extraction, fresh and dry preserved diapausing eggs were washed with MilliQ water. Ethanol preserved samples were re-hydrated for two hours in MilliQ water.

To perform the HotSHOT extraction (see Table 2 for details), individual diapausing eggs were transferred into a $0.2 \mathrm{~mL}$ tube containing $50 \mu \mathrm{L}$ of alkaline lysis buffer under a stereomicroscope. Once in the buffer, the eggs were crushed against the side of the tube using a sterile pipette tip. Samples were incubated at $95^{\circ} \mathrm{C}$ for $30 \mathrm{~min}$ and stored on ice for 3-4 min. A further $50 \mu \mathrm{L}$ of neutralizing buffer was added to each tube, and the samples were vortexed briefly and spun down. Samples were stored at $4^{\circ} \mathrm{C}$ to be used directly in PCR reactions, or at $-20^{\circ} \mathrm{C}$ for a long storage period.

For the Chelex extraction, the diapausing eggs were transferred individually to $0.2 \mathrm{~mL}$ tubes containing $50 \mu \mathrm{L}$ of Instagene Matrix (containing 6\% Chelex resin, Bio-Rad) and crushed against the side of the tube using a sterile pipette tip. The samples were incubated for $30 \mathrm{~min}$ at $60^{\circ} \mathrm{C}$ and $8 \mathrm{~min}$ at $100^{\circ} \mathrm{C}$. Finally, the samples were centrifuged at $14,000 \mathrm{rpm}$ during $5 \mathrm{~min}$, and the supernatant directly used in PCR reaction or stored at $-20^{\circ} \mathrm{C}$ until needed.

Polymerase chain reaction (PCR)-To assess the success of the DNA extractions, a fragment of the mitochondrial gene cytochrome $c$ oxidase subunit I (COI) (ca. 710 bp) was amplified using the LCO1490 and HCO2198 primers (Folmer et al. 1994) or specific primers for the same mitochondrial region modified for Artemia (J. Muñoz, unpublished manuscript). PCR reactions were performed in a total volume of $20 \mu \mathrm{L}$ using $2 \mu \mathrm{L}$ of DNA extract, $1 \times$ PCR buffer, $0.5 \mu \mathrm{M}$ of each primer, 1.5-2.0 mM $\mathrm{MgCl}_{2}, 0.2 \mathrm{mM}$ dNTPs, and 0.4-0.6 U Taq DNA polymerase (Bioline). The thermal profile consisted of a $3 \mathrm{~min}$ initial cycle at $94^{\circ} \mathrm{C}$, followed by 35 cycles of $94^{\circ} \mathrm{C}$ for $45 \mathrm{~s}, 45$ $55^{\circ} \mathrm{C}$ for $1 \mathrm{~min}$, and $72^{\circ} \mathrm{C}$ for $1 \mathrm{~min}$, with a final extension of $72^{\circ} \mathrm{C}$ for $5 \mathrm{~min}$. Five microliters of the PCR product were separated by electrophoresis in $0.5 \times$ SB buffer (Brody and Kern 2004 ) in a $1.5 \%$ agarose gel. Gels were stained with ethidium bromide and visualized under UV in a transilluminator.

\section{Assessment}

To test the performance of the HotSHOT protocol in diapausing stages, we assessed the technique in different groups of zooplankton and compared the results with the Chelex technique. We also tested the success of DNA extraction on old ethanol preserved samples and in diapausing stages of different ages. In addition, we carried out HotSHOT DNA extractions using a range of different total volumes (20-140 $\mu \mathrm{L})$ and quantified the DNA in the extracts. For this, we used diapausing eggs from rotifers and anostracans (the smallest and the largest diapausing eggs used in this study, respectively). Soluble DNA concentration in the HotSHOT extractions was quantified by measuring the absorbance at $260 \mathrm{~nm}$ using a GeneQuant II spectrophotometer (Pharmacia Biotech Co.). No comparison could be done with the Chelex extractions due to unreliable quantification of these extractions with spectrophotometers (JM, JM-P, personal observations).

DNA concentrations obtained with the HotSHOT method in Artemia cysts ranged between 25 and $5 \mathrm{ng} / \mu \mathrm{L}$ for the smallest $(20 \mu \mathrm{L})$ and largest $(140 \mu \mathrm{L})$ total extract volume, respectively, while lower concentrations were obtained for the smaller Brachionus diapausing eggs (maximum $5 \mathrm{ng} / \mu \mathrm{L}$ ). Although in Brachionus the amount of DNA was not high, it was sufficient to perform PCR amplifications with the same success than for Artemia (Fig. 1). Both HotSHOT and Chelex methods resulted in reliable amplifications of diapausing

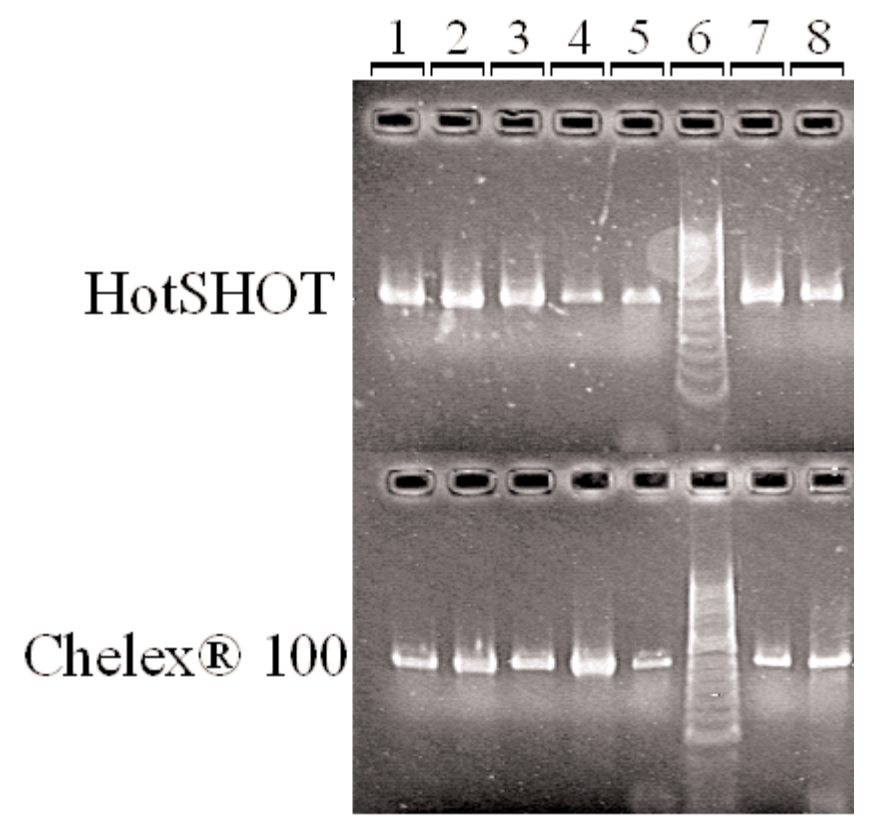

Fig. 1. PCR products of diapausing eggs DNA extractions using HotSHOT and Chelex methods. Samples: $1=$ Brachionus (rotifer); $2=$ unidentified copepod; 3 = Daphnia (cladoceran); 4 = Triops (notostracan); 5 = Artemia (anostracan); $6=100$ bp ladder; 7 = Daphnia from 2000; 8 = Artemia from 1985. More details of sample sources and their preservation history are described in Table 1. 
stages for freshly prepared DNA extractions in fresh and old preserved material, including dry (live) and ethanol-preserved samples, with the HotSHOT method providing slightly stronger bands (see Fig. 1; Table 1).

The success rate for individual cysts DNA extractions with the HotSHOT method (measured indirectly as successful PCR amplifications) was on the order of $97 \%$ for all taxonomic groups, and in tests in rotifers, it increased when only healthy looking eggs were used in the extraction (JM-P, personal observation).

In addition, we successfully tested the HotSHOT technique for various adult zooplanktonic samples (abdomen Artemia, adult Brachionus, whole/half copepod, whole/antenna Daphnia).

In contrast to Chelex preparations, HotSHOT produced long-lasting DNA extractions, as 3-y-old DNA rotifer preparations using this method and stored at $-20^{\circ} \mathrm{C}$ gave clear amplification products for COI and even for a larger fragment of mtDNA genome (1300 bp). These old extracts were also used to reliably score seven microsatellite loci in a large number of samples with no allelic dropout effect (JM-P, unpublished results), indicating that the quality and quantity of the DNA obtained with this method is adequate for PCR-based methods.

\section{Discussion}

We have shown that HotSHOT DNA extractions provide consistent and reliable PCR amplification in diapausing eggs in a range of invertebrate taxa. HotSHOT yielded as good or better results as the widely used Chelex technique in extracting DNA from single diapausing eggs, both for fresh and preserved material (Fig. 1). Although the rate of successful amplifications from both techniques is comparable, HotSHOT presents superior features, such as being a single tube method, which increases the efficiency and eases the implementation of high-throughput processing of diapausing egg samples, and, at the same time, minimizes the risk of cross-sample contamination and success of long-term preservation of DNA samples. The low failure rate in PCR amplifications found in our work is likely to be due to the deteriorated stage of the embryos rather than the age or mode of preservation of the diapausing eggs.

HotSHOT extraction is a highly suitable technique for PCRbased methods such as microsatellite genotyping, restriction fragment length polymorphism (RFLP) analysis, single stranded conformation polymorphism (SSCP) analysis, and sequencing. Its application to other methods requiring high DNA concentrations or high molecular weight DNA could be restricted (Truett et al. 2000).

In summary, the HotSHOT method is a rapid, inexpensive, high-performance technique for PCR-quality DNA extractions from diapausing eggs, which avoids cross-contamination and, as larger volumes are used, it allows for more PCR reactions per sample. In addition, HotSHOT DNA extractions are stable for at least several years. All these advantages make HotSHOT a valuable method to use in diapausing eggs and a superior technique to the widely used Chelex method.
We have provided a protocol to perform high-throughput DNA extraction widely applicable for high-throughput PCRbased genetic screening analyses of virtually all zooplanktonic organisms with diapausing stages in their life cycle. This technique will facilitate the application of large-scale screening molecular techniques in several areas of molecular ecology, from population genetics to barcoding studies.

\section{References}

Adamowicz, S. J., and A. Purvis. 2005. How many branchiopod crustacean species are there? Quantifying the components of underestimation. Global Ecol. Biogeogr. 14:455-468.

Bohonak, A. J., M. D. Holland, B. Santer, M. Zeller, C. M. Kearns, and N. G. Hairston. 2006. The population genetic consequences of diapause in Eudiaptomus copepods. Arch. Hydrobiol. 167:183-202.

Brody, J. R., and S. E. Kern. 2004. Sodium boric acid: a Tris-free, cooler conductive medium for DNA electrophoresis. BioTechniques 36:214-216.

Carlisle, D. B. 1968. Triops (Entomostraca) eggs killed only by boiling. Science 161:279-280.

Carvalho, G. R., and H. G. Wolf. 1989. Resting eggs of lake Daphnia. I. Distribution, abundance and hatching of eggs collected from various depths in lake sediments. Freshw. Biol. 22:459-470.

Cousyn, C., L. De Meester, J. K. Colbourne, L. Brendonck, D. Verschuren, and F. Volckaert. 2001. Rapid, local adaptation of zooplankton behavior to changes in predation pressure in the absence of neutral genetic changes. Proc. Nat. Acad. Sci. U.S.A. 98:6256-6260.

De Meester, L., A. Gómez, B. Okamura, and K. Schwenk. 2002. The Monopolization Hypothesis and the dispersal-gene flow paradox in aquatic organisms. Acta Oecol. Int. J. Ecol. 23:121-135.

Duffy, M. A., L. J. Perry, C. M. Kearns, L. J. Weider, and N. G. Hairston. 2000. Paleogenetic evidence for a past invasion of Onondaga Lake, New York, by exotic Daphnia curvirostris using mtDNA from dormant eggs. Limnol. Oceanogr. 45: 1409-1414.

Edmands, S. 2001. Phylogeography of the intertidal copepod Tigriopus californicus reveals substantially reduced population differentiation at northern latitudes. Mol. Ecol. 10: 1743-1750.

Folmer, O., M. Black, W. Hoeh, R. Lutz, and R. Vrijenhoek. 1994. DNA primers for amplification of mitochondrial cytochrome $c$ oxidase subunit I from diverse metazoan invertebrates. Mol. Mar. Biol. Biotechnol. 3:294-299.

Fontaneto, D. and others. 2007. Independently evolving species in asexual bdelloid rotifers. PLoS Biol. 5:e87.

Gómez, A. 2005. Molecular ecology of rotifers: from population differentiation to speciation. Hydrobiologia 546:83-99.

- and G. R. Carvalho. 2000. Sex, parthenogenesis and genetic structure of rotifers: microsatellite analysis of contemporary and resting egg bank populations. Mol. Ecol. 9:203-214. 
-, G. R. Carvalho, and D. H. Lunt. 2000. Phylogeography and regional endemism of a passively dispersing zooplankter: mitochondrial DNA variation in rotifer resting egg banks. Proc. Royal Soc. London Ser. B-Biol. Sci. 267:2189-2197.

—, M. Serra, G. R. Carvalho, and D. H. Lunt. 2002. Speciation in ancient cryptic species complexes: Evidence from the molecular phylogeny of Brachionus plicatilis (Rotifera). Evolution 56:1431-1444.

Greenspoon, S., M. Scarpetta, M. Drayton, and S. Turek. 1998. QIAamp spin columns as a method of DNA isolation for forensic casework. J. Forensic Sci. 43:1024-1030.

Hairston, N. G. 1996. Zooplankton egg banks as biotic reservoirs in changing environments. Limnol. Oceanogr. 41: 1087-1092.

Hajibabaei, M., and others. 2005. Critical factors for assembling a high volume of DNA barcodes. Phil. Trans. Royal Soc. B: Biol. Sci. 360:1959-1967.

Ishida, S., and D. J. Taylor. 2007. Mature habitats associated with genetic divergence despite strong dispersal ability in an arthropod. BMC Evol. Biol. 7:52.

Limburg, P. A., and L. J. Weider. 2002. 'Ancient' DNA in the resting egg bank of a microcrustacean can serve as a palaeolimnological database. Proc. Roy. Soc. London Ser. B-Biol. Sci. 269:281-287.

Mergeay, J., D. Verschuren, L. Van Kerckhoven, and L. De Meester. 2004. Two hundred years of a diverse Daphnia community in Lake Naivasha (Kenya): effects of natural and human-induced environmental changes. Freshw. Biol. 49:998-1013.

JM-P, unpublished manuscript. Long-term coexistence dynamics of two rotifer sibling species, Ecological Genetics Meeting.

Moorad, J., M. Mayer, and M. Simovich. 1997. Extraction of DNA from anostracan cysts (Crustacea, Branchiopoda) for use in RAPD-PCR analyses. Hydrobiologia 359:159-162.

Onbé, T. 1978. Sugar flotation method for sorting the resting eggs of marine cladocerans and copepods from sea-bottom sediment. Bull. Japan. Soc. Sci. Fish. 44:1411.

Ortells, R., T. W. Snell, A. Gómez, and M. Serra. 2000. Patterns of genetic differentiation in resting egg banks of a rotifer species complex in Spain. Arch. Hydrobiol. 149:529-551.
Proctor, V. W., C. R. Malone, and V. L. DeVlaming. 1967. Dispersal of aquatic organisms: Viability of disseminules recovered from the intestinal tract of captive Killdeer. Ecology 48:672-676.

Reid, V. A., G. R. Carvalho, and D. G. George. 2000. Molecular genetic analysis of Daphnia in the English Lake District: Species identity, hybridization and resting eggs. Freshw. Biol. 44:247-253.

Rudbeck, L., and J. Dissing. 1998. Rapid, simple alkaline extraction of human genomic DNA from whole blood, buccal epithelial cells, semen and forensic stains for PCR. BioTechniques 25:588-592.

Sambrook, J., and D. W. Russell. 2001. Molecular cloning: a laboratory manual, 3rd ed. Cold Spring Harbor Laboratory Press.

Söller, R., K. Warnke, U. Saint-Paul, and D. Blohm. 2000. Sequence divergence of mitochondrial DNA indicates cryptic biodiversity in Octopus vulgaris and supports the taxonomic distinctiveness of Octopus mimus (Cephalopoda: Octopodidae). Mar. Biol. 136:29-35.

Taylor, D. J., P. D. N. Hebert, and J. K. Colbourne. 1996. Phylogenetics and evolution of the Daphnia longispina group (Crustacea) based on 12S rDNA sequence and allozyme variation. Mol. Phylogen. Evol. 5:495-510.

Truett, G. E., P. Heeger, R. L. Mynatt, A. A. Truett, J. A. Walker, and M. L. Warman. 2000. Preparation of PCR-quality mouse genomic DNA with hot sodium hydroxide and Tris (HotSHOT). BioTechniques 29:52-54.

Walsh, P. S., D. A. Metzger, and R. Higuchi. 1991. Chelex-100 as a medium for simple extraction of DNA for PCR-based typing from forensic material. BioTechniques 10:506-513.

Xin, Z., J. P. Velten, M. J. Oliver, and J. J. Burke. 2003. Highthroughput DNA extraction method suitable for PCR. BioTechniques 34:820-826.

Yamaguchi, S. 2000. Phylogenetic and biogeographical history of the genus Ishizakiella (Ostracoda) inferred from mitochondrial COI gene sequences. J. Crustacean Biol. 20:357384 . 